\title{
Sınıflarda Travma Yaşantısı Olan Öğrenciler için Önleyici Bir Tedbir Olarak Tetikleyici Uyarısı Kullanımı
}

\author{
Berk Efe ALTINAL*
}

Öz

Tetikleyici kavramı, travma yaşamış kişilerde kişiyi zihninde travmanın yaşandığı anın anısına geri götüren uyaranları ifade eder. Eğitim ortamlarında, travma yaşantısı olan kişileri bu uyaranların ortaya çıkarabileceği olumsuz deneyimlerden korumak ya da bu uyaranlara maruz kalıp kalmamak konusunda karar noktasında kontrol sahibi olabilmelerini kolaylaștırmak adına tetikleyici uyarılarının kullanılması gerektiği öne sürülmektedir. Bu çalışmada tetikleyici uyarılarıyla ilgili alan yazın ve tartışmalar örneklerle incelenmiştir. Yapılan incelemede "tetikleyici uyarıları" üzerine oluşan literatürde "tetikleyici" ve "travma" kavramlarının psikoloji literatüründe kullanıldığından daha farklı ve daha geniș bir anlamda kullandığı görülmüștür. Alandaki az sayıda görgül çalışma incelenmiştir. Bu çalıșmanın amacı Türkçe yazılı materyal üreten ve eğitim veren kurumları ve kişileri kavramla tanıştırmak ve ileride yapılabilecek yerel görgül çalışmalar için zemin hazırlamaktır.

Anahtar Kelimeler: Travma, Tetikleyici Uyarısı, Mikroagresyon, Eğitim Psikolojisi, Travma Sonrası Stres Bozukluğu

\section{The Use of Trigger Warnings in Classrooms as a Precaution for Trauma-exposed Students}

\begin{abstract}
The concept "trigger" refers to stimuli that might lead the person who has experienced trauma to recall a previous traumatic memory. It has been suggested that, in educational environments, "trigger warnings" should be used to protect people who have been through traumatic experiences from the triggering stimuli and to make it easier for the traumatized person to have control over the decision to be exposed to the triggering stimuli. In this study; the literature and the discussions about "trigger warnings" have been examined with examples. It has been observed that the concepts of "trigger" and "trauma" are used in a different and wider meaning in the literature on "trigger warnings", compared to the usage in standard terminology of psychology. Small number of empirical research on "trigger warnings" has been examined. The purpose of this study is to introduce the concepts to the individuals and the institutions that give education and
\end{abstract}

\section{Derleme Makale (Review Article)}

Geliş/Received: 01.02.2018

Kabul/Accepted: 20.05 .2020

DOI: https://dx.doi.org/10.17336/igusbd.388149

* Öğr. Gör., İstanbul Gelişim Üniversitesi, Sağlık Bilimleri Yüksekokulu, Çocuk Gelişimi (İngilizce)

Programı, İstanbul, Türkiye, E-posta: bealtinal@gelisim.edu.tr ORCID https://orcid.org/0000-0001$\underline{6987-8012}$ 
produce literature in Turkish, and also to provide a groundwork for future empirical studies.

Keywords: Trauma, Trigger Warnings, Microaggressions, Educational Psychology, PTSD

\section{Giriş}

Tetikleyici kavramı, travma sonrası stres bozukluğu olan bireylerde kişiyi zihninde travmanın yaşandığı anın anısına geri götüren uyaranları ifade eder (Colbert, 2017). Tetikleyici ipucu birçok formda olabilmektedir, örneğin travmatik bir kasırga sonrasında rüzgârlı bir hava ya da fiziksel bir saldırı sonrası saldırganı anımsatan görünümde bir kişi tetikleyici uyaran etkisi yaratabilir (Amerikan Psikiyatri Birliği [APA], $2013 ; 275)$

Tetikleyici uyaran, cinsel taciz failinin giydiği klyafetteki bir simge ya da olayı hatırlatan bir yüz ifadesi gibi görsel bir uyaran olabileceği gibi karanlık, kapı çarpması, sigara dumanı vs. gibi çevresel bir uyaran da olabilir. Tetikleyici uyaranlar arasında sözel uyaranlar da vardır; bazı kelimeler ya da ifade etme biçimleri tetikleyici unsur olabilmektedir. Bunların yanı sıra, bedensel bazı tepkiler de tetikleyici ișlevi görebilir, sözgelimi baş travması içeren travmatize edici bir yaşantı sonrasında baş dönmesi hissi tetikleyici işlevi görebilir (APA, 2013; 275)

Geçtiğimiz yıllarda travma yaşantısı olan kişileri bu uyaranların ortaya çıkarabileceği olumsuz deneyimlerden korumak ya da bu uyaranlara maruz kalıp kalmamak konusunda karar noktasında kontrol sahibi olabilmelerini kolaylaștırmak adına tetikleyici uyarılarının kullanılması gerektiği öne sürülmüștür (Colbert, 2017).

$\mathrm{Bu}$ çalışmada travma sonrası stres bozukluğu kavramı açıklanacak, tetikleyici uyarıları ile ilgili tartışmaya değinilecek, arkasından eğitim ortamında tetikleyici uyarılarının kullanımı ve bu kullanımın gerekliliği ve etkililiği konusunda yapılan güncel çalışmalar gözden geçirilecektir. Böylece Türkçe yazılı materyal üreten ve eğitim veren kurum ve kişiler kavramla tanıştırılacak ve ileride yapılabilecek yerel çalışmalar için de zemin hazırlanacaktır.

\section{Travma Kavramı ve Travma Sonrası Stres Bozukluğu}

Travma sonrası stres bozukluğu kavramı, ilk olarak Amerikan Psikiyatri Birliği'nin 1980 yılında yayınladığı Mental Bozuklukların Tanısal ve Sayımsal El Kitabı'nın 3. Baskısında (DSM-III) tanımlanış olsa da, çok eski dönemlerden itibaren savaşa katılan askerler için "nostalji", savaș nevrozu, savaş yorgunluğu gibi bu kavramların işaret ettiği durum günümüzde travma sonrası stres bozukluğu kavramılyla işaret edilen duruma benzerlikler taşır (Colbert, 2017).

Mental Bozuklukların Tanısal ve Sayımsal El Kitabı'nın güncel 5. baskısında travma sonrası stres bozukluğu, kişinin kendi yaşadığı, tanık olduğu, bir yakınının başına geldiğini öğrendiği ya da tekrar tekrar maruz kaldığı, ölüm, ölüm tehdidi, ciddi yaralanma ya da cinsel şiddet olaylarının ardından, bir aydan daha uzun süre boyunca ilgili olay anına sürekli zihinsel olarak geri dönmesi, olumsuz anıları istem dışı hatırlaması, olaya dair tekrar eden kâbuslar görmesi, olayı anımsatan uyaranların etkisiyle yoğun stres ve fizyolojik tepkiler vermesi şeklinde tanımlanmaktadır (APA, 2013; 271).

Bu tanıyı gündeme getiren vakalar ilk etapta Vietnam savaşında görev almış ve bu esnada travmatize edici deneyimler yaşamış Amerika Birleşik Devletleri askerleri olduğundan, travma sonrası stres bozukluğu salt savaş ve askeri yaşamla ilişkili bir durum olarak algılanabilmektedir. Travma sonrası stres bozukluğu gerçekten de yaygın 
olarak askerler, polisler, itfaiye görevlileri, tıbbi acil servis çalışanları gibi meslekleri gereği travmatize edici olaylarla karşılaşma olasılıkları yüksek olan kişiler arasında yaygın olarak görülmektedir (APA, 2013; 276). Ancak savaş ve askeri çatışmaların yanı sıra, tecavüz ve cinsel taciz, etnik veya politik motivasyonlarla tutsaklık ve soykırım gibi durumların ardından hayatta kalan kişiler arasında da travma sonrası stres bozukluğu sıklıkla görülmektedir (APA, 2013; 276).

Colbert (2017), ABD'de yaşayan her altı kadından birinin tecavüz yaşantısı olduğuna ve travma sonrası stres bozukluğunun tecavüz sonrası hayatta kalan kișilerde yoğun olarak görüldüğüne dikkat çekmekte, tetikleyici uyarıları ile ilgili taleplerde tecavüz konusunun ön plana çıkmasının bu durumla bağlantılı olduğunu öne sürmektedir.

\section{Tetikleyici Uyarılarının Tarihi ve Kullanım Amacı}

Tetikleyici uyarıları ilk olarak internet üzerinden yayın yapan feminist yayınlarda ve çevrimiçi forumlarda, cinsel taciz, tecavüz, saldırı ve benzeri olayları yaşamış ya da bunlara şahit olmuş okuyucuları travma sonrası stres bozukluğu belirtilerini tetikleyebilecek, kötü hissettirebilecek ya da başka güçlü duygusal tepkilere sebep olabilecek içeriklerle ilgili uyarmak amacıyla kullanılmaya başlanmıştır (Schmidt, 2015).

İnternet üzerinde yayın yapan sitelerde bașlayan bu uyarı geleneği daha sonra başta üniversiteler olmak üzere başka alanlara da taşınmıştır. 2015 yılında ABD'de pek çok üniversitede öğrenciler ders materyallerinde, konuşmalarda, ders müfredatlarında ve katılmanın müfredat gereği gerekli tutulduğu her türlü ortamda öğrencilerin olumsuz duygusal tepkilere sebep olabilecek içerikle ilgili olarak uyarılmasını talep etmeye başlamıştır. Bunun yanı sıra öğrenciler, stres ve olumsuz duygular yaratabilecek içerik ve fikirlerden muaf tutulmayı da talep etmiștir (Lukianoff \& Haidt, 2015; Shulevitz, 2015). $\mathrm{Bu}$ taleplerde öğrenciler tarafından stres ve olumsuz duygular yaratabileceği öne sürülmüş içerik ve fikirler arasında tecavüz; fiziksel, duygusal ve cinsel istismar; çocuk istismarı; kendine yönelik zarar davranışları; yeme bozuklukları; yasal, yasadışı ve psikiyatrik ilaç kullanımı; intihar; savaș görüntüleri; cinsel ilișkide rıza konusunda tartışmalar; hamilelik ve çocuk doğurma; ırklar; ișsizlik; çok kültürlülük gibi konular yer almaktadır. (Robbins, 2016) Ayrıca "tetikleyici" ifadesinin kendisinin silahlarla, askeri yaşantılarla ve savaşla ilgili travma deneyimi olan kişilerde travma sonrası stres bozukluğu semptomlarını uyandırabileceği düşünülerek "tetikleyici uyarısı" ifadesinin yerine "içerik uyarısı" ifadesinin kullanılması gerektiği de öne sürülmüştür (Colbert, 2017)

Yukarıda listelenen konularla ilișkili olarak dile getirilen "Hangi ülkeden geliyorsun?" ya da "Bence bir iși kim hak ediyorsa o kazanmalı" gibi ifadelerin bir kısmı mikroagresyon olarak görüldüğünden gücendirici, incitici ve stres yaratıcı oldukları öne sürülmektedir. Mikroagresyon kavramı 1970'li yıllarda Harvard üniversitesinden Chester M. Pierce tarafından ortaya atılmış olsa da yakın zamanlarda Columbia Üniversitesi profesörü Derald Wing Sue tarafından yeniden gündeme getirilmiş ve ardından yaygın olarak kullanılmaya başlanmıștır. (Robbins, 2016) Sue, mikroagresyon kavramını şöyle tanımlar:

"Mikroagresyonlar, zamanla üst üste eklenerek biriken kısa, güç algılanan ve çoğunlukla bilinçdışı sözel hakaretler, düşmanca, ırkçı, cinsiyetçi, homofobik ya da başka içeriklerdeki hakaretleri ileten eylemler ya da aşağılama içeren mesajlardır." (Sue, 2010)

Mikroagresyon içeren ifadeler ilk etapta herhangi bir ayrımcılık, aşağılama ya da başka bir incitici unsur içermiyor gibi görünse de içeriğinde bilinçli ya da bilinçsiz bir biçimde ayrımcı ya da aşağılayıcı bir yön bulunmakta, bunlar sürekli olarak tekrarlanmakta ve kişi üzerinde bir noktadan sonra göz ardı edilemez biçimde incitici hale gelmekte ve olumsuz hisler uyandırmaktadır. Ross-Sheriff (2012), 
mikroagresyonların kasti, aleni ya da sürekli tekrarlanan bir yapıda olmadığında dahi incitici etkiye sahip olabileceklerini öne sürmüștür.

Tetikleyici uyarıları kimi üniversitelerde öğretim üyeleri tarafından gönüllü olarak kullanılmaya başlanmıştır. Kimi üniversiteler ise öğretim üyelerine bu tarz uyarıları yapmaları konusunda öneride bulunmaktadır. Örneğin Amerika Birleşik Devletlerinde Oberlin Üniversitesi böyle bir öneride bulunmuş fakat daha sonra gelen eleştiriler ve özellikle üniversitedeki öğretim üyelerinden gelen itirazlardan sonra bu önerisini geri çekmiştir. Öneri metninde öğretim üyelerine tetikleyicilerin ne olduğunu anlamaları, bu tarz içeriklerle ilgili öğrencileri uyarmaları ve eğer cinsel tacizle ilgili ya da herhangi bir imtiyaz ve ayrımcılıkla ilgili tetikleyici olabilecek bir içerik dersin konusu ve öğrenim hedefleri ile doğrudan ilgili değilse ya da başka bir materyal ile ikame edilebiliyorsa materyali kullanmaktan vazgeçmeleri önerilmiştir. Metinde ayrıca tetikleyici uyarılarının derste nasıl söze döküleceğine dair birkaç örnek bulunmaktadır. Bunlar şu şekildedir:

- "Bu film hakaret ve hatta fiziksel şiddet formunda irkçllı içeren sahnelere sahiptir, ancak bu filmin amacının ırkçılığı ifşa etme ve ırkçllığa karşı çıkma olduğunu düşünüyorum ve bu yüzden bu film bizim konumuz için önemli."

- "Bu yapıtı yazarın ırkçı bakış açısına rağmen okuyoruz çünkü bu çalışma antropolojinin temel kurucu eserlerinden biridir ve bence kitabın savlarına karşı çıkabilir, onu yapısökümüne uğratabilir ve yazarın hatalarından dersler çıkarabiliriz."

- "Bu belgesel heteroseksizme önemli bir şekilde karşı çıkıyor ve konuyu burada tartışmamı hayati önem taşıyor. Bence bu belgeseli izlemenin ve tartışmanın kendimizdeki heteroseksizmi sorgulama noktasında bize faydası dokunabilir."

Tetikleyici uyarılarına bir başka örnek Hostos Üniversitesinde tarih dersleri veren Angus Johnston'un (2014) kullandığı metin olabilir:

"Ders İçerik Notu: Bu dönem zaman zaman oldukça rahatsızlık verici, hatta kimi ögrenciler tarafından travmatik olarak değerlendirilebilecek bazı tarihsel olayları tartışıyor olacağız. Bu tartışmalar esnasında dışarı çıkmak ister ya da kısa süreliğine mola vermek isterseniz herhangi bir akademik yaptırım olmadan bunu yapabilirsiniz. (Ancak kaçırdığınız materyallerle ilgili sınavda sorumlu tutulacaksınız. Ĕger derslikten uzun süreliğine ayrılırsanız, lütfen bir başka öğrenci arkadașınızdan ders notlarını edinin ya da benimle görüşün). Eğer ders materyaline ilişsin kişisel tepkilerinizi tartışmak isterseniz gerek sınıf içinde gerekse özel olarak bu tarz tartışmalar gerçekleştirmeyi ders için uygun bir çalışma olarak değerlendirerek hoş karşılamaktayım." (Johnston, 2014)

Tetikleyici uyaranlarında amaç travma sonrası stres bozukluğu yaşayan öğrenciyi ders materyallerinden uzaklaştırmak ve bazı materyalleri okumamak ya da çalışmamak için bir bahane sunmak değil, söz konusu öğrenciyi gereksiz bir tetiklenmeden korumak ya da eğer materyali kullanması gerekliyse önceden kendini hazırlamasını sağlamaktır. Örneğin Cornell Üniversitesinde Felsefe dersleri veren Manne (2015) derslerde tetikleyici olabileceğini tahmin ettiği içeriklerden önce konuyla ilgili uyarıda bulunarak incinebilir öğrencilere kendilerini hazırlama imkânı sunduğunu öne sürmektedir. Öğrenci materyalle hazırlıksız bir şekilde yüzleşmek yerine anksiyeteyle başa çıkmakta etkili olduğu bilinen yöntemleri kullanarak ve hatta belki de bir psikiyatrist tarafından reçetelendirilmiş bir sakinleştirici kullanarak kendini materyale hazırlayacak, böylece potansiyel bir panik atak ya da benzeri bir kriz durumundan kendini sakınmış olacaktır. 


\section{Tetikleyici Uyarılarının Kullanım Sıklığı}

2015 yılında Amerika Birleşik Devletlerinde Sansüre Karşı Ulusal Koalisyon'un yaptığı (ancak bir hakem kurulunun gözetiminden geçmemiş) anket çalışmasında öğretim üyelerinin sadece \%12'sinin tetikleyici uyarılarını düzenli olarak kullanıldığı ve ankete katılan öğretim üyelerinin önemli bir kısmının öğrencilerinden bu konuda herhangi bir talep almadığı (\%85) ya da birkaç kez talep aldıkları (\%13) bulgulanmıştır. Bu ankete katılan öğretim üyelerinin $\% 45$ 'i tetikleyici uyarılarının öğretim üzerinde olumsuz etkiye sahip olduğu ve \%63'ü akademik özgürlüğü olumsuz etkilediği yönünde görüş bildirmiştir. (NCAC, 2015).

İntihar, yeme bozukluğu, cinsel taciz gibi bir dizi tetikleyici olabileceği öne sürülen unsuru ders konusu olarak içeren Anormal Davranışlar dersini veren öğretim üyeleri üzerinde yapılan bir çalışmada ise öğretim üyelerinin travma sonrası stres bozukluğu semptomlarını tetikleyebilecek içeriklerle ilgili öğrencileri uyarma gereği duymadıklarını ve çoğunlukla tetikleyici uyarıları konusunda nötr ya da negatif bir tutuma sahip oldukları bulgulanmıştır (Boysen, Wells, Dawson, 2016).

\section{Tetikleyici Uyarısı Kullanımına Yönelik İtirazlar}

Tetikleyici uyarılarına ilişkin talep pek çok üniversite öğretim üyesi tarafından şüphe ile karşılanmaktadır. Sözgelimi Amerikan Üniversite Profesörleri Derneği (AAUP) 2014 yılında yayınladığı Tetikleyici Uyarıları Hakkında başlıklı metinde tetikleyici uyarılarının zorunlu tutulmasının ya da önerilmesinin ders içi materyallere ve öğretme tekniklerine müdahale olacağı ve bunun da akademik özgürlükleri kısıtlayacağı öne sürülmüş, ders ortamının öğrencileri zorlayıcı değil koruyucu bir ortam olması gerektiği iddiasını anti-entelektüel ve çocuklaştırıcı olmakla itham etmiştir. Metinde, tetikleyici uyarılarının gönüllü olarak kullanılmasının da bir dizi probleme yol açacağı savunulmuştur:

"Bu tarz tetikleyici uyarlları istisnai kişisel deneyimlerden kaynaklanan travma ile bütün bir grubu etkilemesi beklenen travmayı birbirine karıştırmakta ve bireylerin belli bazı içeriklere olumsuz tepki vereceklerini varsaymaktadır. Tetikleyici uyarısı öğrencinin yükümlü olduğu bir metni okumamasına yol açabileceği gibi metnin tek bir yönüne odaklanmalarını ve metne başka bir tepki vermelerini engelleyerek öğrencilerin normalde vermeyecekleri tepkileri ortaya çıkarabilir."(AAUP, 2014)

Kanada Üniversite Öğretmenleri Birliği ise tetikleyiciler ile rahatsızlık verici konuların birbirine karıștırılmaması gerektiği uyarısını yapmakla birlikte, öğrencilerin derslerde zaman zaman rahatsız edici uyaranlarla karşılaşabileceğini ve buna hazırlıklı olmaları gerektiğini, çeşitli uyaranlardan dolayı travma sonrası stres bozukluğu semptomları tetiklenen öğrencilerin ise tıbbi destek almaya yönlendirilmeleri gerektiğini savunmuştur (CAUT, 2015).

Tetikleyici uyarılarına getirilen başka bir eleștiri ise travma sonrası stres bozukluğu terapilerinde kullanılan maruz bırakma yöntemi üzerinden getirilmiștir. $\mathrm{Bu}$ yöntemde travma sonrası stres bozukluğu, fobi ya da panik atak yaşayan kişi kontrollü bir ortamda aşamalı olarak tetikleyici uyarana maruz bırakılır. Bu yöntemin etkililiği kapsamlı çalışmalarla gösterilmiştir. Remembering Trauma kitabının yazarı psikoloji profesörü Richard J. McNally (2016), tetikleyici uyarılarının kişiyi tetikleyici uyarandan sürekli koruyarak bu uyaranla etkileşime girmesinin önünde bir engel teşkil ettiği ve bunun terapilerde amaçlanın tam tersi olduğunu öne sürmüştür.

McNally'nin (2016) bu itirazı terapi ortamının dinamikleri ile ders ortamının dinamikleri birbirinden farklı olduğunu göz ardı ettiği yönünde eleştirilmiştir. Manne’ye (2015) göre kişi terapiye kendi isteğiyle yardım alma amacı güderek gider ve terapide 
belli yüzleşmeler ya da sıkıntılar yaşayabileceğini kabul ederek yaşanacaklara rıza verir, tüm bu sıkıntı verici süreç boyunca ruh sağlığı profesyonellerinin gözetiminde olacak, gerektiğinde ruhsal ve tıbbi yardım alabilecektir. Dahası kişi tetikleyici uyaranla, travma sonrası anksiyeteyi iyileștirmek amacıyla kontrollü bir biçimde aşamalı olarak yüzleștirilecek, sistematik olarak uyarana karşı duyarsızlaşması sağlanacaktır. Bu durum kişinin sınıfı geçmesi ve yüksek bir not ortalaması tutturmak için ders içi materyallere odaklanmak zorunda olduğu ve karşısına beklemediği bir anda tetikleyici bir uyaranın çıktığı bir ortamdan tamamıyla farklıdır. Kişinin tetikleyici uyaranlarla ilgili olarak uyarıldığı, kendisini bu uyaranlara hazırlamasına müsaade edildiği kontrollü bir ortam tetikleyici stresörün etki şiddetini azaltabileceği gibi, böyle bir ortam terapi ortamına daha yakın olacaktır. Yukarıda da belirtildiği gibi tetikleyici uyarısının amacı kişiyi tetikleyici olabilecek uyarandan sakınmak değil, bu uyaranla etkileşime girmeden önce kendisini hazırlaması için uygun ortam sağlamak ve kişinin karşılaşacağı içerik üzerindeki kontrolünü arttırmaktır (Manne, 2015).

\section{Travma ve Tetiklenme Kavramlarının Çerçevesini Belirlemek}

Yukarıda değinilen tartışmalarda vurgulanması gereken bir nokta hem tetikleyici uyarısıyla ilgili taleplerde bulunan öğrencilerin, hem de konuyla ilgili düzenlemeler öneren ya da karşı çıkan açıklamalarda bulunan öğretim üyelerinin travma ve tetikleyici kavramlarını psikolojide kullanıldığından daha geniş bir manada ve oldukça serbest bir biçimde kullandıklarıdır. Tetikleyici kavramı, kişide rahatsızlık uyandıran, herhangi bir negatif his uyandıran konu, görüntü, ifade ya da tartışma için kullanılmıștır (Carter, 2015). Yukarıda da ele alındığı gibi Kanada Üniversite Öğretmenleri Birliği bu noktaya dikkat çekerken, travma sonrası stres bozukluğu yaşayan öğrenciler için psikiyatrik yardıma vurgu yapmış, psikolog McNally (2016) de benzer bir beyanda bulunmuștur.

Carter (2015) ise bu bakıș açısında bir dizi problem olduğunu iddia eder. Carter'a göre tetiklenme deneyimi kişiyi travma anına geri götürerek ve yeniden travmatize ederek kișinin bilgiye ve tartışmaya erișimini engeller. Bu durum bir engellilik durumu olarak ele alınmalı ve sınıf ortamı erişilebilirlik bakış açısından düzenlenmelidir. "Travma sonrası stres bozukluğu yaşayan öğrenciler tıbbi yardım almaya gönderilmelidir" şeklindeki yaklaşımlar mevzuyu kişisel düzleme indirgeyerek sorunun toplumsal boyutunu yok saymakta ve erişebilirlikle ilgili mevzuyu kişisel psikiyatrik rahatsızlık mevzusuna dönüștürmektedir. Carter (2015), Ulusal Eğitim İstatistik Merkezi'nin raporlarına dikkat çekerek psikiyatrik engeli olan öğrencilerin okulu bırakma oranlarının diğer tüm gruplardan daha yüksek olduğunu, okulu bırakma sebepleri arasında "zihinsel hastalıklar"ın \%56.1, "ciddi duygusal rahatsızlıklar"ın ise \%23.6 oranlarında olduğunu vurgulamaktadır. Dahası, ögrencilerin bu sorunlarla ilgili yardım almalarının önünde çeşitli engeller bulunmaktadır: ifşa olma korkusu (\%24), bu hizmetleri alabileceği konusunda bilgisizlik (\%19), stigmatizasyon (damgalanma) endișesi (\%19) ve bu hizmetlerin sunulmuyor olması (\%16) (Collins \& Mowbray, 2005). Carter'a (2015) göre üniversitelerde hâlihazırda engellilere ve psikiyatrik engellere yönelik bir ayrımcılık söz konusudur ve erişilebilirlikle ilgili taleplerin "akademik özgürlükler" sebep gösterilerek reddedilmesi ve tetikleyici uyaranlarla ilgili problem yaşayan öğrencilerin ders materyallerinden kaçmaya çalışan aşırı hassas ve "çocuksu" kişiler olarak gösterilmesinin bu ayrımcılığın bir parçasıdır.

Dahası, travmaya sebep olan yaşantılar her ne kadar kişilerin başına tesadüfen geliyor gibi görünse de, cinsel taciz, tecavüz, fiziksel şiddete maruz kalma, savaş deneyimleri ve benzeri travma yaratan olaylara maruz kalmanın irkla, cinsiyetle ve toplumsal cinsiyetle, cinsel yönelim ve cinsel kimliklerle, ekonomik sinıfla ve diğer toplumsal kimlik ve tabakalarla alakalı olduğu göz ardı edilemez. Bu sebeple Carter'a 
(2015) göre, çeşitli toplumsal arka planlardan gelen öğrencilerin mevcut olduğu sınıflarda bu kişilerin yaşamış olabilecekleri travmatik olayları ve bunların daha sonra sebep olduğu zihinsel ve fiziksel etkileri ve acıları göz ardı etmek engellilere yönelik ayrımcılığın yanı sıra ırkçılıkla, cinsiyetçilikle, hetero-cis-seksizmle ve sınıfsal ayrımcılıkla da alakalı olarak düşünülmelidir.

\section{Tetikleyici Uyarıları: Görgül Çalışmalar}

Tetikleyici uyarılarının çevrimiçi medyada kullanımının yaygınlaşması ve konunun üniversiteler dâhilinde tartışılıyor olması konu üzerine görgül bazı çalışmalar yapılmasının da önünü açmıştır. Tetikleyici uyarılarının etkilerine ve işlevselliğine dair sınırlı sayıda görgül çalıșma bulunmakla beraber, bu konu üzerine alan yazın karmaşık sonuçlara sahiptir.

Bellet, Jones ve McNally (2018) tetikleyici uyarılarının, bu uyarıları alan kişilerin strese sebep olabilecek uyaranlara karşı dirençliliği üzerine bir çalışma yürütmüşlerdir. $\mathrm{Bu}$ çalışmada, travma geçmişi olmayan katılımcılardan dünya edebiyatından okuyan kişide strese sebep olacağı öngörülen pasajlar okumaları istenmiș, kontrol grubuna pasajdan önce herhangi bir uyaran verilmezken, deney grubuna okuyacakları metnin öncesinde içerikle ilgili bir tetikleyici uyarısı verilmiștir. Katılımcılara bunların yanı sıra takiben düşük miktarda stres yaratacağı öngörülen birer metin daha okutulmuştur. Katılımcıların stres seviyeleri ve psikolojik dayanıklılık inançları ölçülmüştür. Bulgular, tetikleyici uyaranlarm strese sebep olabilecek metinlere ve okutulan daha az stres sebebi olabilecek metinlere yönelik kaygı tepkileri üzerinde anlamlı bir etkileri olmadığı yönündedir. Ancak tetikleyici uyarıları, kelimelerin bireyler üzerinde hasar bırakabileceği yönünde güçlü inançlara sahip katılımcılarda stres yaratabilecek metinlere yönelik anlık kaygı tepkilerini arttırmıştır. Öte yandan, tetikleyici uyaranları, katılımcıların kendilerinin ve başka insanların travmatize edici bir deneyimden sonra psikolojik olarak hasar almaya daha açık olarak algılama seviyelerini artırmıştır.

Bellet ve diğerleri (2020) aynı dizaynı travma geçmişi olmayan üniversite öğrencileri ile tekrarlamıştır. Bu çalışmada tetikleyici uyaranlarının stres seviyeleri üzerinde anlamlı bir etkiye sahip olmadığı bulgusu yeniden elde edilmiştir; ancak kelimelerin bireyler üzerinde hasar bırakabileceği yönünde güçlü inançlara sahip katılımcların tetikleyici uyarısı sonrasında stres yaratabilecek metinlere yönelik anlık kaygı tepkilerinin arttığına yönelik bulgu bu çalışmada tekrarlanamamıştır. Her iki çalışmada da, tetikleyici uyarılarının, travma geçmişi olmayan kişilerde kaygı tepkilerinin azalmasını sağladığı yönündeki iddiayı doğrulamayan bulgular ortaya çıkmıştır.

Gainsburg ve Earl (2018) ise tetikleyici uyarılarını bir kișilerarası duygu kontrolü aracı olarak ele almaktadır; buna göre, tetikleyici uyarısı vermek başkalarının gelecekteki duygusal tepkilerini öngörerek, ortaya çıkabilecek olumsuzlukları azaltma stratejisidir. Çalışmada, tetikleyici uyarılarının katılımcıların negatif duygulanım beklentilerini arttırdığı ve uyarı aldıktan sonra takip eden yazıdan ya da videodan kaçınma olasılıklarının yükseldiği bulgulanmıștır. Öte yandan, kontrol grubu ile karşılaştırıldığında, tetikleyici uyarısı alan kişilerin makaleyi okuduktan sonra daha düşük seviyede negatif duygulanım beyan ettikleri görülmüştür. Tetikleyici uyaranlarının bireyleri koruyabildiği inancına sahip olan kişilerde metni okuduktan sonra ortaya çıkan negatif duygulanım daha azdır ve metinden kaçınma olasılığı daha yüksektir.

Bridgland, Green, Oulton ve Takarangi'nin (2019) araştırması önceleme etkisi (Collins \& Loftus, 1975; Baumgartner \& Wirth, 2012; Janiszewski \& Wyer, 2014) üzerine çalışmalara dayanmaktadır; bu sebeple strese sebep olacağı öngörülen uyaranlar yerine belirsiz ve yoruma açık görseller uyaran olarak kullanılmıştır. Çalışmada, tetikleyici uyarılarının görsellere bakmadan önce yaşanan kaygıyı, negatif duygulanımı ve olumsuz 
beklentileri arttırdığı bulgulanmıştır. Bu bulgular, tetikleyici uyarılarının önceleme etkisine sebep oldukları ve bireyleri olumsuz bir uyarana dair beklentiye soktukları yönündeki hipotezi doğrulamıștır. Ancak tetikleyici uyarısının görsellere bakıldıktan sonra uyarılma seviyeleri üzerinde küçük bir miktar olumsuz etkisi ölçülmüş olsa da bu etki anlamlı seviyede değildir. Araştırmacılar, tetikleyici uyaranlarının bu uyarıyı alan bireylerde kaygıya sebep olmadığı ancak kaygıyı azaltacak bir etkiye de sahip olmadığı sonucuna varmışlardır. Öte yandan, çalıșmada tetikleyici uyarısı katılımcılara sunulduğunda, katılımcılardan bir kısmı deneye devam etmeme kararı vermiştir. Tetikleyici uyarısı verilmeyen kontrol grubu ile karşılaştırıldığında aynı süre içinde deneyi tamamlamadan bırakma oranı anlamlı seviyededir. Bu da, strese sebep olabilecek uyaranlara karşı kendisini korumak isteyen bireylerin bu uyaranlardan uzak durmak için tetikleyici uyarılarını kullanabildiklerini gösteren bir bulgu olarak yorumlanmıștır.

Sanson, Strange ve Gary (2019) ise tetikleyici uyarılarının kişileri stresten ve olumsuz etkilerden korumadığı ancak stres ve kaygının anlamlı miktarda artmasına da sebep olmadığını bulgulamıştır. Katılımcılar, tetiklenme uyarısı aldıkları ve almadıkları koşullarda kendilerine sunulan içeriklerden aynı şekilde etkilenmiş, deneyimledikleri negatif duygulanımlar anlamlı miktarda farklılaşmamıștır.

Boysen, Isaacs, Tretter ve Markowski'nin (2019) araștırmasında, cinsel saldırı ve intihar konularındaki derslerde tetikleyici uyarısı kullanımı konu edinilmiștir. Araştırmanın bulguları tetikleyici uyarılarının, derslerde ortaya çıkan duygulanım üzerinde anlamlı bir etkiye sahip olmadığını göstermektedir. Bununla birlikte, derslerden önce tetikleyici uyarısı verildiği koşulda, bu konu konuşulmadan önce böyle bir uyarının verilmesinin gerekli olduğu yönündeki inançta artış görülmüştür.

Jones, Bellet ve McNally'nin (basım aşamasında) çalışmaları ise travma yaşantısı olan ya da travma sonrası stres bozukluğu tanısı almış olan bir örneklemle çalışılıyor olması bakımından önceki çalışmalardan ayrılmaktadır. Çalışmada Benett ve diğerlerinin (2018) araştırma modeli tekrarlanmıştır. Travma yaşantısı olan bireylerde, travma sonrası stres bozukluğu tanısı almış kişilerde, travma sonrası stres bozukluğu semptom kriterlerini karşılayan kişilerde ve araştırma içerisinde geçmiş travmalarıyla eşleșen uyaranlarla karşılaștığını beyan eden kişilerde, strese sebep olabilecek uyaranlardan önce sunulan tetikleyici uyarılarının kaygı seviyelerinde anlamlı bir azalmaya sebep olmadığı bulgulanmıştır. Tetikleyici uyarılarının etkisi, kaygıyı azaltmaktan ziyade, önemsiz miktarda da olsa arttırmak olmuştur. Çalışmanın bir diğer bulgusu, travma yaşantısı olan kişilerin tetikleyici uyarılarını, içerikten uzak durmak için kullanmadıkları yönünde olmuştur. Tetikleyici uyarısı verilen deney grubu ile böyle bir uyarı almayan kontrol grubu arasında çalışmayı yarıda bırakmak ya da gelecek olan metinleri okumamak yönünde anlamlı bir fark bulgulanmamıștır. Araștırma ayrıca, tetikleyici uyarılarının travma yaşantısı olan kişilerin travmayı kendi yaşam anlatılarının daha merkezi bir öğesi olarak algılamalarına sebep olabildiğini bulgulamıștır. Araștırmacılar, travma yaşantısını yaşam öyküsünün merkezi bir öğesi olarak görmenin kişinin iyileşme sürecine olumsuz etki yapabileceğine dikkat çekerek, tetikleyici uyarılarının zararlı olabileceğini öne sürmektedir.

\section{Sonuç ve Tartışma}

Geçtiğimiz yıllarda, ders ortamlarında travma sonrası stres bozukluğu semptomları gösteren kişileri travma anına geri dönmek ve travmaya bağlı semptomlarından korumak ya da bu tanıyı almış kişilerin derslere ve ders materyallerine tamamen erişebilmesini sağlamak iddiasıyla çeşitli talepler ve uygulamalar gündeme gelmiştir. Bu uyarılar, erişilebilirlik ve ayrımcı olmayan ders ortamı kurma ilkeleri öne sürülerek savunulmuş, akademik özgürlüklerin korunması, öğrencilerin sıkıntı verici 
materyalle başa çıkmayı öğrenmesi gerektiği gibi gerekçelerle bu uyarılara karşı çıkılmıştır. Ayrıca, tetikleyici uyaranların sağaltıcı amaçlarla kullanıldığı terapi ortamlarına referans verilerek bu uyarılara karşı çıkılmış olsa da, hem sınıf ortamı ile terapi ortamı hem de bu iki ortamda bu uyaranlarla karşılaşma biçimleri birbirlerinden oldukça farklı olduklarından bu karşı çıkış yeterince gerekçelendirilmemiştir. Son olarak tetikleyici terimi zaman zaman psikopatolojideki anlamından farklı olarak çok geniş bir anlamda, öğrenciler için rahatsızlık verici olabileceği öne sürülen her konuyu kapsayacak biçimde kullanılmıştır. Bu yüzden kavramın netleştirilmesi ve doğru bir çerçeveye oturtulması önem taşımaktadır.

Gerek tetikleyici uyarılarının dersliklerde kullanım sıklığı gerekse bu uyarıların ders içi eğitimin kalitesine ve öğrenciler açısından erişebilirliğin artışına olumlu ve olumsuz etkilerini ölçebilecek görgül çalışmalar sınırlı sayıdadır. Mevcut alan yazın, tetikleyici uyarılarının etkileri konusunda karmaşık sonuçlar sunmaktadır.

Görgül çalışmalar, tetikleyici uyarıların travma geçmişi olmayan kişilerde anlamlı bir olumlu ya da olumsuz etkiye sahip olmadığı (Bellet vd., 2018, 2020; Boysen vd., 2019) ya da çok küçük bir etkiye sahip olduğunu (Bridgland vd., 2019; Sanson vd., 2019) gösteriyor gibi görünmekle beraber, tetikleyici uyarılarının kaygı verici ve tetikleyici uyaranlardan uzak durmak isteyen bireylerin işine yarayabiliyor olabileceğini gösteren bulgular da (Bridgland vd., 2019) vardır. Ancak konu üzerine çalışmalar henüz sınırlı sayıdadır. Tetikleyici uyarılarının ası amacının travma sonrası stres bozukluğu semptomları gösteren bireyleri yaşayabilecekleri olumsuzluklardan korumak olsa da, alan yazında örneklemi travma yaşantısı olan kişilerin oluşturduğu görgül çalışmalar fazlasıyla sınırlıdır. Travma yaşantısı olan ya da travma sonrası stres bozukluğu tanısı alan bireylere odaklanan bir çalıșma, tetikleyici uyarılarının travmayı yaşam anlatısının merkezine yerleștirerek iyileșme sürecine zarar verebileceğini öne sürmektedir (Jones vd., basım aşamasında).

Tetikleyici uyarılarının kullanımının standart bir uygulama haline getirilmesinden önce bu uyarıların etkilerinin anlaşılması için daha fazla görgül çalışmaya ihtiyaç olduğu açıktır. Tetikleyici uyarılarını eğitimin bir parçası haline getirmeden önce, öğrenciler arasında travma sonrası stres bozukluğu semptomlarının yaygınlığının bilinmesi, eğitimcilerin ders içi materyalleri sunarken bu konuda hangi uyarılarda bulunuyor olduklarına ve hassas içeriklere dair mevcut baş etme stratejilerine ve son olarak bu tarz uyarıların travma yaşantısı olan ve olmayan bireyler üzerindeki etkilerine dair daha fazla çalışmaya ihtiyaç vardır.

\section{KAYNAKÇA}

AAUP (American Association of University Professors) (2014). On Trigger Warnings, https://www.aaup.org/report/trigger-warnings (Erişim Tarihi 2017, 8 Ağustos)

Amerikan Psikiyatri Birliği [APA] (2013). Diagnostic and Statistical Manual of Mental Disorders 5. Baskl (DSM-5) American Psychiatric Association, Washington, DC. BAUMGARTNER, S. E., \& WIRTH, W. (2012). Affective priming during the processing of news articles. Media Psychology, 15(1), 1-18. beliefs. Journal of Experimental Social Psychology, 79, 252-263. doi: 10.1016/j.jesp.2018.08.006

BELLET, B. W., JONES, P. J., \& McNALLY, R. J. (2018). Trigger warning: Empirical evidence ahead. Journal of Behavior Therapy and Experimental Psychiatry, 61, 134-141. doi: 10.1016/j.jbtep.2018.07.002

BELLET, B. W., JONES, P. J., MEYERSBURG, C. A., BRENNEMAN, M. M., MOREHEAD, K. E., \& McNALLY, R. J. (2020). Trigger warnings and resilience in college 
students: A preregistered replication and extension. Journal of experimental psychology: Applied. doi: 10.1037/xap0000270

BOYSEN, G. A., ISAACS, R. A., TRETTER, L., \& MARKOWSKI, S. (2019). Trigger warning efficacy: The impact of warnings on affect, attitudes, and learning. Scholarship of Teaching and Learning in Psychology. doi: 10.1037/stl0000150

BOYSEN, G.A., WELLS, M.W., DAWSON, K.J. (2016). Instructors' Use of Trigger Warnings and Behavior Warnings in Abnormal Psychology. Teaching of Psychology. Vol. 43(4) 334-339 doi: 10.1177/0098628316662766

BRIDGLAND, V. M., GREEN, D. M., OULTON, J. M., \& TAKARANGI, M. K. (2019). Expecting the worst: Investigating the effects of trigger warnings on reactions to ambiguously themed photos. Journal of Experimental Psychology: Applied, 25(4), 602617. doi: $10.1037 /$ xap0000215.

CARTER, A. M. (2015). Teaching with trauma: Trigger warnings, feminism, and disability pedagogy. Disability Studies Quarterly, 35(2), 10. doi:

10.18061/dsq.v35i2.4652

CAUT (Canadian Association of University Teachers) (2015) Trigger Warnings. https://www.caut.ca/about-us/caut-policy/lists/caut-policy-statements/triggerwarnings (Erişim Tarihi 2017, 8 Ağustos)

Clinical Psychological Science, 7, 778-793. doi: 10.1177/2167702619827018

COLBERT, S. (2017). Like Trapdoors. A History of Posttraumatic Stress Disorder and the Trigger Warning. Knox, EJM (ed). Trigger Warnings: History, Theory, Context, içerisinde. Rowman \& Littlefield. 3-21

COLLINS, A. M., \& LOFTUS, E. F. (1975). A spreading-activation theory of semantic processing. Psychological review, 82(6), 407.

COLLINS, M. E., \& MOWBRAY, C. T. (2005). Higher education and psychiatric disabilities: national survey of campus disability services. American Journal of Orthopsychiatry, 75(2), 304. doi: 10.1037/0002-9432.75.2.304

GAINSBURG, I., \& EARL, A. (2018). Trigger warnings as an interpersonal emotion-regulation tool: Avoidance, attention, and affect depend on beliefs. Journal of Experimental Social Psychology, 79, 252-263. doi: 10.1016/j.jesp.2018.08.006

JANISZEWSKI, C., \& WYER Jr, R. S. (2014). Content and process priming: A review. Journal of Consumer Psychology, 24(1), 96-118. doi: 10.1016/j.jcps.2013.05.006

JOHNSTON, A, (2014). Why I'll Add a Trigger Warning. Inside Higher Ed. https://www.insidehighered.com/views/2014/05/29/essay-why-professor-addingtrigger-warning-his-syllabus (Erişim Tarihi 2017, 9 Ağustos)

JONES, P. J., BELLET, B. W., \& McNALLY, R. J. (Basım Aşamasında). Helping or Harming? The Effect of Trigger Warnings on Individuals with Trauma Histories. Clinical Psychological Science Erişim: osf.io/9eapn

LUKIANOFF, G., \& HAIDT, J. (2015, Eylül). The coddling of the American mind.

The Atlantic. http://www.theatlantic.com/magazine/archive/2015/09/the-coddling-ofthe-american-mind/399356/ (Erișim Tarihi 2017, 8 Ağustos)

MANNE, K. (2015, 19 Eylül). Why I Use Trigger Warnings. The New York Times. https://www.nytimes.com/2015/09/20/opinion/sunday/why-i-use-triggerwarnings.html (Erişim Tarihi: 2017, 8 Ağustos)

McNALLY, R.J. (2016, 13 Eylül) If You Need a Trigger Warning, You Need P.T.S.D. Treatment, The New York Times. https://www.nytimes.com/roomfordebate/2016/09/13/do-trigger-warnings-work/ifyou-need-a-trigger-warning-you-need-ptsd-treatment (Erişim Tarihi 2017, 8 Ağustos)

MILLER-LEONARD, T. (2014, 27 Şubat) A.S. Senate Passes Proposal to Label Trauma-Provoking Academic Content. Daily Nexus. http://dailynexus.com/2014-02- 
27/a-s-senate-passes-proposal-to-label-trauma-provoking-academic-content/ (Erişim Tarihi 2017, 8 Ağustos)

NCAC (National Coalition Against Cencorship) (2015), What's the Truth About Trigger Warnings? http://ncac.org/wp-content/uploads/2015/11/NCACTriggerWarningReport.pdf (Erişim tarihi: 2017, 4 Aralık)

Oberlin University, Office of Equity Concerns (2013) Prevention, Support and Education: Support Resources for Faculty. Sexual Offense Resource Guide. http://web.archive.org/web/20131222174936/http:/new.oberlin.edu/office/equityconcerns/sexual-offense-resource-guide/prevention-support-education/supportresources-for-faculty.dot (Erişim Tarihi 2017, 8 Ağustos)

ROBBINS, S.P. (2016) From the Editor-Sticks and Stones: Trigger Warnings, Microaggressions, and Political Correctness, Journal of Social Work Education, 52:1, 1-5. doi:: 10.1080/10437797.2016.1116850

ROSS-SHERIFF, F. (2012). Microaggression, women, and social work. Affilia, 27, 233-236. doi:10.1177/0886109912454366

SANSON, M., STRANGE, D., \& GARRY, M. (2019). Trigger warnings are trivially helpful at reducing negative affect, intrusive thoughts, and avoidance. Clinical Psychological Science.7(4) 778-793 doi: 10.1177/2167702619827018

SCHMIDT, P. (2015, June 16). Many instructors embrace trigger warnings, despite their peers' misgivings. Chronicle of Higher Education.

http://chronicle.com/article/Many-Instructors-Embrace/230915 (Erişim Tarihi 2017, 8 Ağustos)

SHULEVITZ, J. (2015, 21 Mart). In college and hiding from scary ideas. New York Times Sunday Review. http://www.nytimes.com/2015/03/22/opinion/sunday/judithshulevitz-hiding-from-scary-ideas.htm (Erişim Tarihi 2017, 8 Ağustos)

SUE, D. W. (2010). Microaggressions in everyday life: Race, gender, and sexual orientation. Hoboken, NJ: Wiley

WILSON, J. P. (2004). PTSD and Complex PTSD: Symptoms, Syndromes, and Diagnoses. WILSON, J. P., \& KEANE, T. M. (Eds.). Assessing psychological trauma and PTSD. içerisinde. Guilford Press.

\section{Summary}

The concept "trigger" refers to stimuli that might lead the person who has experienced trauma to recall a previous traumatic memory. A trigger can be a visual stimulus such as a logo, an environmental stimulus such as a malodor or darkness, or a linguistic/paralinguistic stimulus such as a word, a question or a certain vocal tone. Being exposed to a triggering stimulus might lead the person to face various experiences ranging from a minor discomfort to more serious ones such as flashbacks to the moment of trauma or panic attack.

It has been suggested that, in educational environments, "trigger warnings" should be used to protect people who have been through traumatic experiences, from the triggering stimuli; and to make it easier for the traumatized person to have control over the decision of being exposed to the triggering stimuli. In order to do that, authors and educators are suggested to inform the receivers about potentially triggering subjects or materials that will be presented or discussed. For instance, if a course contains references to sexual abuse, it is suggested that the students should be informed before they select the course, against the possibility that some of the students might be survivors of sexual abuse and the discussion of the sexual abuse in the classroom might trigger some unwanted thoughts or feelings and cause symptoms. 
In the early 2000s, the idea of "trigger warnings" started to circulate in feminist blogs and journals. As students began demanding trigger warnings in the universities; the concept became a widely discussed topic among university students and scholars in North America. Demands for trigger warnings also sparked concerns for the freedom of speech on campuses. Alongside with the concerns about freedom of speech, it has been stated that trigger warnings might also be counterproductive for the educational environment and cause a distraction considering the real problems in campuses (see AAUP, 2014 and CAUT, 2015).

This statements against the use of trigger warnings have been criticized by others. Carter (2015) states that this argument of "academic freedom" is actually a part of the discrimination against disabled people, particularly, people with psychiatric disabilities. Carter also remarks that it is statistically more probable that people who have a disadvantaged background (such as low socioeconomic status or having a minority identity) would have traumatic experiences and ignoring the consequences of this experiences would be equal to ignoring the disadvantaged in society and might be considered as a form of discrimination.

In this study; the literature and the discussions about "trigger warnings" have been examined with examples. During this examination, two problems on the current discussion have been observed.

Firstly, it has been observed that the concepts of "trigger" and "trauma" are used in a different and wider meaning in the literature on trigger warnings, compared to the usage in the standard terminology of psychology.

Secondly, even though there are many strong opinions on the issue, empirical studies that are available in the current literature offer complex results on the effects of trigger warnings.

Empirical studies show that trigger warnings do not have a significant positive or negative effect in people with no history of trauma (Bellet et al., 2018, 2020; Boysen et al., 2019) or they have trivial impact (Bridgland et al., 2019; Sanson et al. ., 2019). There are also findings that suggest that trigger alerts might be useful for individuals who want to avoid anxious and triggering stimuli (Bridgland et al., 2019). However, studies on the subject are still few. Although the main purpose of the trigger warnings is to protect the individuals who suffer from posttraumatic stress disorder from the negativities they may experience, the empirical studies of the sample of people with trauma experience are limited in the literature. A study focusing on the individuals with PTSD suggests that trigger warnings might have a worsening effect on the healing process by placing trauma at the center of the life narrative of the person (Jones et al., In press).

This study introduces the concepts to the individuals and the institutions that give education and produce literature in Turkish, and also provides a groundwork to the future empirical studies. The study suggests that the concepts should be defined and framed clearly, and following a better conceptual framework, more empirical research should be conducted. 